abolished the dyskinesias but increased the akinesia and rigidity. When the dose of Sinemet-275 was increased to six tablets daily, however, he was normally mobile for an average of $7 \cdot 2 \mathrm{~h}$ and had no dyskinesias during the day. Overall an optimum dose of oxiperomide produced subjective and objective improvement in five of the six patients. When oxiperomide was discontinued and replaced by placebo at the end of the trial dyskinesias returned or increased in all patients tested.

Side effects of oxiperomide were uncommon. One patient complained of apathy, another complained of impotence. In two patients episodes of profuse sweating were relieved by oxiperomide. No changes were detected in pulse or blood pressure and blood counts and results of kidney and liver function tests remained unchanged after repeated laboratory examinations.

Effect of single dose ( 5 or $10 \mathrm{mg}$ by mouth) of oxiperomide on symptoms in 13 patients with various spontaneous dyskinesias

\begin{tabular}{|c|c|c|c|c|c|}
\hline Diagnosis & $\begin{array}{c}\text { No of } \\
\text { patients }\end{array}$ & $\begin{array}{c}\text { Age } \\
\text { (years) }\end{array}$ & Sex & $\begin{array}{c}\text { Mean } \\
\text { decrease in } \\
\text { dyskinesia } \\
\text { score* } \\
\text { (“.,) }\end{array}$ & $\begin{array}{c}\text { No in } \\
\text { whom } \\
\text { dyskinesia } \\
\text { score } \\
\text { improved } \\
\text { by } 40^{\prime \prime} . \\
\text { or more }\end{array}$ \\
\hline $\begin{array}{l}\text { Huntington's chorea } \\
\text { Gilles de la Tourette's }\end{array}$ & 3 & $46-62$ & $2 \mathrm{M} ; 1 \mathrm{~F}$ & 37 & 2 \\
\hline $\begin{array}{l}\text { syndrome } \\
\text { Generalised torsion }\end{array}$ & 1 & 33 & $M$ & 52 & 1 \\
\hline $\begin{array}{c}\text { Generalised torsion } \\
\text { dystonia }\end{array}$ & 5 & $13-42$ & $2 \mathrm{M} ; 3 \mathrm{~F}$ & 10 & 1 \\
\hline Spasmodic torticollis & 2 & $32-39$ & $1 \mathrm{M} ; 1 \mathrm{~F}$ & 20 & 1 \\
\hline Orofacial dystonia & 2 & $42-54$ & $1 \mathrm{M} ; 1 \mathrm{~F}$ & 46 & 1 \\
\hline
\end{tabular}

* Severity of dyskinesia was scored before and two to three hours after oxiperomide, when drug reached peak effect.

\section{SPONTANEOUS DYSKINESIAS}

Single 5 or $10 \mathrm{mg}$ doses of oxiperomide decreased abnormal movements by $40 \%$ or more in the patient with Gilles de la Tourette's syndrome, in two of the three patients with Huntington's chorea, in one of the five patients with generalised torsion dystonia, in one of the two patients with orofacial dystonia, and in one of the two patients with spasmodic torticollis. The effect was noticeable after about 90 minutes and lasted four to six hours. Side effects were common. Eight patients complained of drowsiness, though they did not fall asleep, and the change in intensity of dyskinesias was not attributable to this subjective complaint. One patient developed typical akathisia with restlessness, forced rocking, and pacing. None had drug-induced Parkinsonism.

\section{Discussion}

Our study shows that oxiperomide can (a) diminish dyskinesias induced by dopamine agonists in patients with Parkinson's disease without necessarily increasing the akinesia and rigidity of the illness, and (b) reduce the intensity of spontaneous dyskinesias in patients with tics and chorea, and to a less extent in those with torsion dystonia, without causing druginduced Parkinsonism. We conclude that the dopaminergic mechanisms responsible for dyskinesias, whether drug-induced or spontaneous, are not identical with those concerned in the relief of Parkinsonism. Other well-known clinical observations have hinted at this possibility-for example, levodopa and other dopamine agonists may cause dyskinesias without relieving Parkinsonism. Nevertheless, our experiments with oxiperomide show that drug-induced dyskinesias can be abolished without increasing Parkinsonism, whereas the antidyskinetic actions of drugs such as haloperidol" and pimozide ${ }^{3}$ have been inseparable from their capacity to increase Parkinsonism.

Our results provide evidence to support the concept that more than one population of dopamine receptors exist in the brain. ${ }^{1}$ In practical terms oxiperomide is not the ideal drug to control dyskinesias, for it causes unacceptable drowsiness. Our study shows, however, that it is worth pursuing the search for selective dopamine antagonists to solve the problems of druginduced and spontaneous dyskinesias.

We thank Janssen Pharmaceutica for supplies of oxiperomide and placebo and fruitful discussion. Paul Bédard was a fellow of the R S McLaughlin Foundation of Canada on leave from the Laboratoires de Neurobiologie, Faculté de Médecine, Université Laval, Quebec, Canada.

\section{References}

${ }^{1}$ Marsden, C D, in Modern Trends in Neurology-5, ed D Williams, p 141. London, Butterworth, 1975.

2 Klawans, H L, and Weiner, W J, fournal of Neurology, Neurosurgery and Psychiatry, 1974, 37, 427.

3 Tarsy, D, Parkes, J D, and Marsden, C D, fournal of Neurology, Neurosurgery and Psychiatry, 1975, 38, 331.

${ }^{4}$ Cool A R, and Van Rossum, J M, Psychopharmacologia, 1976, 45, 243.

${ }^{5}$ Costall, B, and Naylor, R J, European fournal of Pharmacology, 1975, 33, 301.

\title{
Viral infections in travellers from tropical Africa
}

\author{
A W WOODRUFF, E T W BOWEN, G S PLATT
}

British Medical fournal, 1978, 1, 956-958

\section{Summary and conclusions}

Examination of sera from 86 travellers to Britain from tropical Africa disclosed evidence of past infection with 10 identifiable viruses, of which the most important were O'nyong-nyong, dengue, chikungunya, and Ntaya. The findings indicate that infection with $O$ 'nyong-nyong may be acquired sporadically in Nigeria, Ghana, and Sierra Leone, where it has not previously been identified. Chikungunya infection had not been recorded in West Africa other than Nigeria and Senegal. Patients from Sierra Leone and contiguous Liberia had antibodies to this infection. An outbreak of dengue fever in the Seychelles

in early 1977 was confirmed. Ntaya virus, though known in Uganda, Cameroon, and Zaire, appears also to be transmitted in Kenya, Nigeria, and Zambia. Clinical studies indicated that chikungunya infection may present with alimentary features, possibly with jaundice. The clinical features of Ntaya infection may include bizarre neurological manifestations in addition to fever. The absence of Lassa antibodies among these travellers suggested that this infection is not a common hazard among such persons.

\section{Introduction}

The main purpose of this study was to determine whether patients who had suffered from fever while in tropical Africa 
Virus antibodies detected in serum from 15 patients who had travelled from tropical Africa to Britain between November 1975 and 7 une 1977

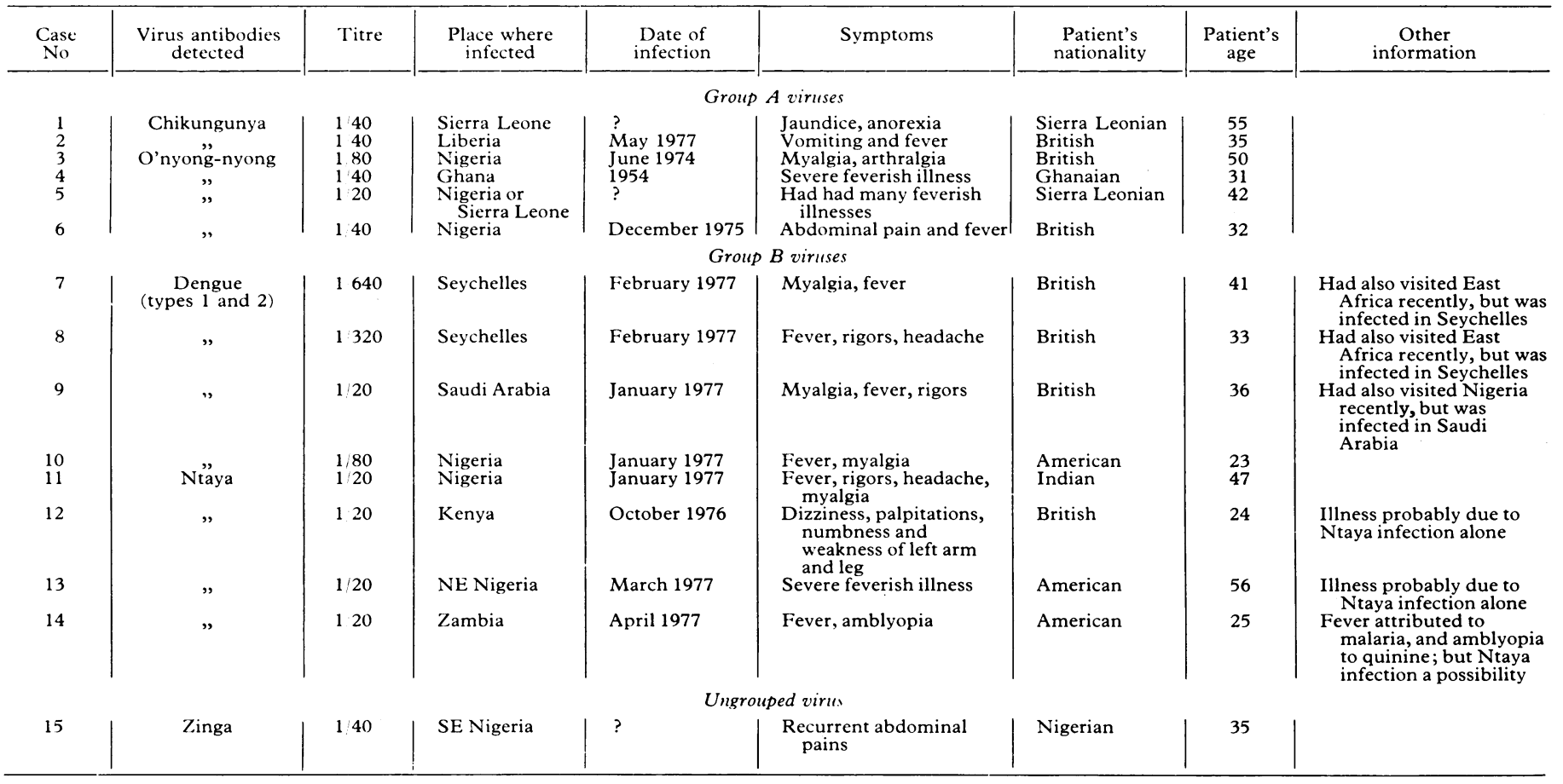

had, in fact, had Lassa fever and thus to see whether Lassa fever is a common or uncommon cause of pyrexia of undetermined origin among travellers in that part of the world. A further aim was to determine as far as possible what viral infections such travellers had contracted in the past. In this way we hoped not only to discover a cause of some pyrexia of otherwise undetermined origin but also to find where outbreaks of particular infections were occurring. This information would be of value in diagnosing the cause of fever encountered among others coming from that region, and we thought that it might disclose current outbreaks of public health importance; for example, in 1973 the diagnosis of Lassa fever in a patient in London had pointed to an important outbreak of the disease in Sierra Leone. ${ }^{1}$

\section{Patients and methods}

Patients attending this hospital as outpatients or admitted to the medical unit were routinely questioned about previous illnesses, and those who when in tropical Africa had had a distinct feverish illness causing incapacity and for which the cause had not been determined gave a blood sample for virus studies. Samples of serum were stored at $4 \mathrm{C}$ and sent to the Microbiological Research Establishment, where they were examined for Lassa fever antibodies and antibodies to a wide range of African viruses -57 in all. Haemagglutination inhibition, complement fixation, and indirect immunofluorescence techniques were used.

\section{Results}

Out of 86 patients examined, $15(17 \cdot 4 \%)$ had demonstrable evidence of 22 attacks of illness caused by viruses. Antibodies to 10 different viruses were detected in the sera from these patients, and in several, more than one antibody was present. The detection of these infections

Medical Unit, Hospital for Tropical Diseases, London NW1 OPE A W WOODRUFF, MD, FRCP, physician and director

Microbiological Research Establishment, Porton

E T W BOWEN, MIBIOL, FIMLs, head of special pathogens unit G S PLATT, FIMLS, scientific officer among the 86 patients entailed carrying out 4902 tests for virus antibodies. In several cases it was possible to identify with some precision the time and place at which the infection had been contracted. In others, particularly when patients had travelled widely over considerable periods or had had several feverish illnesses within the preceding few years, such identification was not possible.

Evidence of two infections with chikungunya virus was found (see table); one patient (case 3 ) had a positive reaction for chikungunya virus at a haemagglutination inhibition titre of $1 / 40$ but for O'nyongnyong virus at a titre of $1 / 80$. In three patients the serum contained O'nyong-nyong antibodies only, with no cross-section with other antigens. Three patients had only dengue (types 1 and 2) antibodies in their serum; a fourth gave a reaction, possibly a cross-reaction with Uganda $S$ antigen. The result of the haemagglutination inhibition test for Uganda $S$ infection was also positive at a titre of $1 / 20$ in the serum of a patient (case 11) who gave a positive reaction at the same dilution against Ntaya antigen. Cross-reactions between these two antigens cannot be excluded. In the sera of three patients only Ntaya virus antibodies were detected. These patients had been in Africa for short periods and had had only one febrile illness; thus probably the illness was associated with Ntaya infection, a virus for which the clinical features of infection have not been recorded. In the serum of one patient only Zinga virus antibodies were detected; this virus has only twice been isolated from man. Antibodies to Wesselsbron and Banzi viruses were detected in the serum of one patient along with others against Uganda $S$ and dengue types 1 and 2 . Wesselsbron virus has been isolated from only six persons, and Banzi from one; no case of Uganda $S$ infection has yet been observed with certainty in man. Our patient (case 10) may therefore have suffered from dengue infection, the antibodies to which were cross-reacting with Uganda S, Wesselsbron, and Banzi antigens. No antibodies to Lassa fever virus were found. This indicates that Lassa fever is not a common infection among travellers in Africa who suffer from feverish illnesses.

\section{Discussion}

Several points of epidemiological and clinical and diagnostic importance arise from this study.

\section{EPIDEMIOLOGICAL RESULTS}

Chikungunya virus is known to have caused several epidemics both in Africa and, more recently, in India. The first identifiable 
chikungunya epidemic was in Tanzania in 1952-3, and the virus has been isolated in East Africa, Zaire, Rhodesia, Senegal, Nigeria, and the Far East. Serological surveys have disclosed its presence in many parts of West Africa." Thus the detection of antibodies in two travellers to Britain from Sierra Leone and Liberia respectively is consistent with the known distribution of this virus.

O'nyong-nyong virus is known particularly for having caused an epidemic in East Africa beginning in 1959 and affecting some two million people. From virus isolations it is known to have occurred in Senegal as well as East Africa, but it has not been reported from Ghana, Sierra Leone, or Nigeria, from which countries three travellers came and in whose serum only O'nyong-nyong virus antibodies were present. Apparently, therefore, sporadic transmission is occurring at widely disseminated points in West Africa in addition to Senegal, where it has been isolated.

Dengue virus is associated more with Asia than with Africa, although it is well known to be endemic in Africa. Our findings indicate that transmission of the virus occurred in Nigeria in January 1977. In the Seychelles an epidemic of dengue fever occurred in the early part of 1977 , and two of our patients who had been to Africa and to the Seychelles had developed dengue fever in the Seychelles (cases 7 and 8).

Ntaya virus - Three patients had only Ntaya antibodies in their serum and had contracted definable illnesses in northeastern Nigeria, Kenya, or Zambia. The known distribution from virus isolation of this infection is in Uganda, Cameroon, and the Central African Republic. Serological surveys have disclosed antibodies to Ntaya virus in Tanzania, Egypt, and the Far East. Our results indicate that in addition to these regions the infection is endemic in Nigeria, Kenya, and Zambia.

Zinga virus has been isolated only in the Central African Republic, and serological surveys have indicated its presence in Zaire. ${ }^{2}$ It is of particular interest, therefore, that the patient in whose serum Zinga virus antibodies were detected had lived in south-eastern Nigeria for most of his life, a region not far distant from the known distribution of $Z$ inga virus.

\section{CLINICAL AND DIAGNOSTIC RESULTS}

Chikungunya infection-Several hundreds of patients have been observed with chikungunya infection, and the predominant clinical picture has been of myalgia with fever, headache, conjunctival injection, and sometimes haemorrhagic signs. Both patients in this series who had had unmistakable chikungunya infection not only came from contiguous countries but had an alimentary presentation of their disease, one with vomiting and fever, and the other with fever, anorexia, and jaundice. Thus it would probably be worth while to investigate the possibility of chikungunya infection among patients in that part of the world who have such alimentary symptoms associated with fever and other known symptoms of the infection.

O'nyong-nyong fever-The oustanding clinical picture in this illness is of severe joint pains, backache, headache, and anorexia, symptoms that to a greater or less degree were encountered in our patients.

Ntaya infection-The three patients in whose serum only Ntaya virus antibodies were present were of particular interest, for no human cases of infection with this virus have previously been recorded. In one patient the presumed Ntaya virus illness had been with severe malaise, fever, headache, and myalgia. In a second case there had been bizarre neurological manifestations, with dizziness and numbness and weakness of the left leg and arm. In the third patient a fever presumed to have been caused by malaria was associated with severe amblyopia and restriction of the peripheral visual fields. During the six months after this illness the visual acuity and restriction of the visual field were reported to have vastly improved. Although there can be no certainty, it appears to be worth while to consider Ntaya virus infection as a possible cause of fever associated with bizarre neurological manifestations in tropical Africa.

Zinga infection-The one patient who had only Zinga antibodies in his serum had lived in south-eastern Nigeria for most of his life and had had several episodes of abdominal pain and of ill-defined fever but distinctive features suggestive of Zinga virus infection could not be identified.

Lassa fever-Keane and Gilles ${ }^{3}$ suggested that mild infections with Lassa virus may not be uncommon in Africa. In our series of 86 patients, however, all of whom had had one or more feverish illnesses while in Africa, some of them severe, there was no evidence of Lassa fever having occurred. Probably, therefore, Lassa fever occurs in limited outbreaks and at infrequent intervals, as is indeed suggested by reports of this infection. With the exception of the focus in Sierra Leone, where transmission appears to have been proceeding for several years, known outbreaks of Lassa fever have all been explosive and circumscribed both in time and place, an observation of considerable epidemiological, public health, and clinical importance.

We acknowledge a grant from the Department of Health and Social Security, which facilitated this study. We are grateful to Dr D I H Simpson for comments.

\section{References \\ 1 Woodruff, A W, et al, British Medical fournal, 1973, 3, 616. \\ 2 Burge, P O, International Catalogue of Arboviruses, 2nd edn. US Depart- ment of Health, Education and Welfare. Public Health Service. Washington, 1975 . \\ ${ }^{3}$ Keane, E, and Gilles, H M, British Medical fournal, 1977, 1, 1399.}

(Accepted 16 February 1978)

\section{SHORT REPORTS}

\section{Reliable prediction of coronary disease using treadmill exercise testing}

Coronary arteriography is the only method of selecting patients with coronary artery disease suitable for bypass surgery. The large numbers of patients with chest pain necessitates an accurate non-invasive test which will identify those with significant coronary artery disease. Conventional treadmill exercise testing using ST segment displacement gives few false-positive results but fails to detect about $20 \%$ of patients with important coronary artery disease. ${ }^{12}$ Using a modification of an exercise index described by Papazoglou, ${ }^{3}$ we have reduced substantially this high incidence of false-negative results.

\section{Patients, methods, and results}

Altogether 57 men and 13 women aged between 35 and 66 (average 50) were studied by subjective maximal treadmill testing using the Bruce protocol. ${ }^{4}$ All had been selected on clinical grounds, and treadmill tests were performed without knowledge of the arteriographic findings. All drugs were discontinued before testing. By using a modified ECG V5 bipolar lead system $(\mathrm{CM} 5)^{4}$ the heart rate and ST segment displacement were measured by computer during exercise and recovery. The normal range of ST segment dis- 